\title{
Cocos nucifera $L$. endosperm promotes healing of excised wound in BALB/c mice
}

\author{
Erna C. AROLLADO ${ }^{1,2, *}$, Arlene A. SAMANIEGO ${ }^{3}$, Rohani B. CENA ${ }^{4}$, Josephine D. AGAPITO ${ }^{5}$, Leslie B. TOMAGAN ${ }^{1}$, \\ Kerstin Mariae G. PONSARAN ${ }^{1}$, Richelle Ann M. MANALO ${ }^{1}$, Gerwin Louis T. DELA TORRE ${ }^{1}$

\begin{abstract}
Institute of Pharmaceutical Sciences, National Institutes of Health, University of the Philippines Manila, Ermita, Manila, Philippines
College of Pharmacy, Department of Pharmacy, University of the Philippines Manila, Ermita, Manila, Philippines

Department of Anatomy, College of Medicine, University of the Philippines Manila, Ermita, Manila, Philippines

Institute of Molecular Biology and Biotechnology, National Institutes of Health, University of the Philippines Manila, Ermita, Manila, Philippines
\end{abstract} \\ Department of Biology, College of Arts and Sciences, University of the Philippines Manila, Ermita, Manila, Philippines
}

\begin{abstract}
Mature endosperm of Cocos nucifera L. (family Arecaceae) has been used in folkloric medicine as wound healing agent. However, valuable scientific evidence of its traditional use has not yet been verified. This study evaluates the wound healing activity of $C$. nucifera endosperm on the excised wound in BALB/c mice. Three concentrations (30\%, $60 \%$ and $90 \%)$ of $C$. nucifera endosperm were prepared as ointment using petroleum jelly as base. The safety of the formulation was evaluated using dermal irritation test. The prepared concentrations, Solcoseryl $1^{\circ}$ ointment (positive control) and petroleum jelly (negative control) were topically applied daily on the excised wound and observed for wound healing activity for 14 days, with histological evaluations at days 7 and 14 . The $90 \%$. nucifera endosperm ointment showed no clinical signs of dermal irritation during the study duration, confirming the safety for topical usage of all the $C$. nucifera formulation. All groups demonstrated scab formation and wound contraction at days 7 and 9, respectively. Healing of the wounds, manifested by distinct wound contraction, was observed at day 14, with $60 \%$ C. nucifera endosperm exhibiting significant activity compared to the negative control $(p=0.009)$ and untreated $(p=0.046)$ groups. It also displayed the highest activity, with notable similarity in the activity of Solcoseryl $l^{\circ}$, and revealed the most organized epidermis comparable to normal skin. This study validates the folkloric use of $C$. nucifera endosperm in facilitating wound healing process, with $60 \%$ C. nucifera endosperm exhibiting the most desirable activity.
\end{abstract}

KEYWORDS: Cocos nucifera; endosperm ; wound healing ; dermal irritation.

\section{INTRODUCTION}

A wound is defined as disruption of normal structure and function of skin and other tissues. As skin serves as an important barrier that protects our body from harmful elements in the environment, fast and efficient healing is necessary to restore its structure and function [1]. Various complications, such as dehisced wounds [2-3], hypertrophic scarring due to excessive scar formation, and contracture formation resulting to exaggeration of normal wound edge contraction forming deformities, leads to abnormal wound healing that may affect the life of patients, particularly their psychosocial aspect [4]. Although there are already available wound healing products in the market, such as topical antimicrobial and advanced dressings, negative pressure wound devices, growth factor applications, skin substitutes and hyperbaric oxygen, issues with drug resistance and side effects, and the cost of these products may hamper the effective management of wounds [5]. This problem drives the interest of many researchers to look for other sources

Received: 02.08.2017 / Accepted: 08.11.2017

Corresponding Author: Erna C. AROLLADO

E-mail: ecarollado@up.edu.ph

Phone: (+632) 5772001

ORCID No: 0000-0003-1997-4609 of wound healing agents that are not only cheap and readily available, but also effective and safe to use.

Cocos nucifera L. (Family Arecaceae), commonly known as coconut, is an important fruit crop in tropical countries, recognized to be a "wonder fruit" because every part of it proves to be useful. It is a ready source of food and drink to most Filipinos and has been used in traditional medicine by many cultures. The coconut water obtained from the fruit is utilized for various health benefits such as an oral rehydration agent for diarrhea [6] and antiseptic drink for urinary tract infection while the endosperm is used for processing of different edible products [7]. Antigenotoxic effects of coconut milk, water and endosperm were also observed on bone marrow cells of experimental mice [8]. The oil from C. nucifera endosperm has also been used as antioxidant [9], antimicrobial [10] and wound healing agents [11].

Although there are already studies involving the use of virgin coconut oil as wound healing agent, limited knowledge on

\footnotetext{
How to cite this article: Arollado EC, Samaniego AA, Cena RB, Agapito JD, Tomagan LB, Ponsaran KMG, Manalo RAM, Dela Torre GLT. Cocos nucifera L. endosperm promotes healing of excised wound in BALB/c mice. Marmara Pharm J. 2018; 22 (1): 103-109.
} 
the utilization of $C$. nucifera endosperm as a source material for wound treatment remains. This study is advantageous as it will decrease the processes necessary for the extraction of oil, which leads to lowering of the product cost. Thus, this exploratory study is helpful in formulating a less expensive topical agent for the treatment of wounds.

\section{RESULTS}

\subsection{Dermal irritation test}

The skin areas of both male and female rabbits treated with G3 formulation displayed no clinical signs of irritation, depicted as erythema and edema. Thus, the PII values were zero, suggesting that the formulation is non-irritating. Furthermore, the skin of the rabbits on all areas tested were intact throughout the 72-h observation period.

\subsection{Wound healing activity}

Among the treatment groups, PC and UN groups started to display wound contraction on day 7 and 11 of the experiment, respectively (Figure 1), while the remaining groups exhibited wound contraction on day 9. All groups presented distinct wound contraction on day 14 . Also, on day 14 , only G2 $(p=0.009)$ and PC $(p=0.046)$ displayed significant wound healing activity with NC but only G2 was significantly different with UN $(p=0.046)$. It is important to note that G2

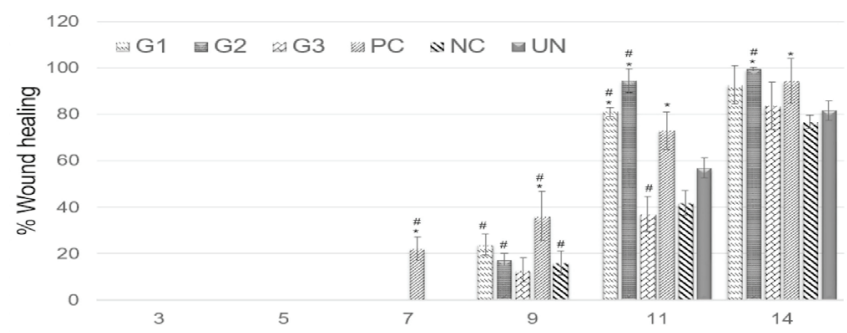

Figure 1. Percent wound healing activity of different treatment groups in excision wound model of BALB/c mice from day 0 (baseline) to day $14.30 \%$ C. nucifera endosperm ointment (G1), $60 \%$ C. nucifera endosperm ointment (G2), 90\% C. nucifera endosperm ointment (G3), Solcoseryl $l^{\oplus}$ ointment (positive control, PC), petroleum jelly (negative control, NC), untreated (UN). * - Significant difference with negative control group, \# - Significant difference with untreated group. demonstrated the highest activity comparable with that of PC. Inflammation was observed on the site of excision on day 3 of the experiment (Figure 2). Full scab formation was apparent on day 7 on all groups, following evident wound size reduction on day 9 thereafter.

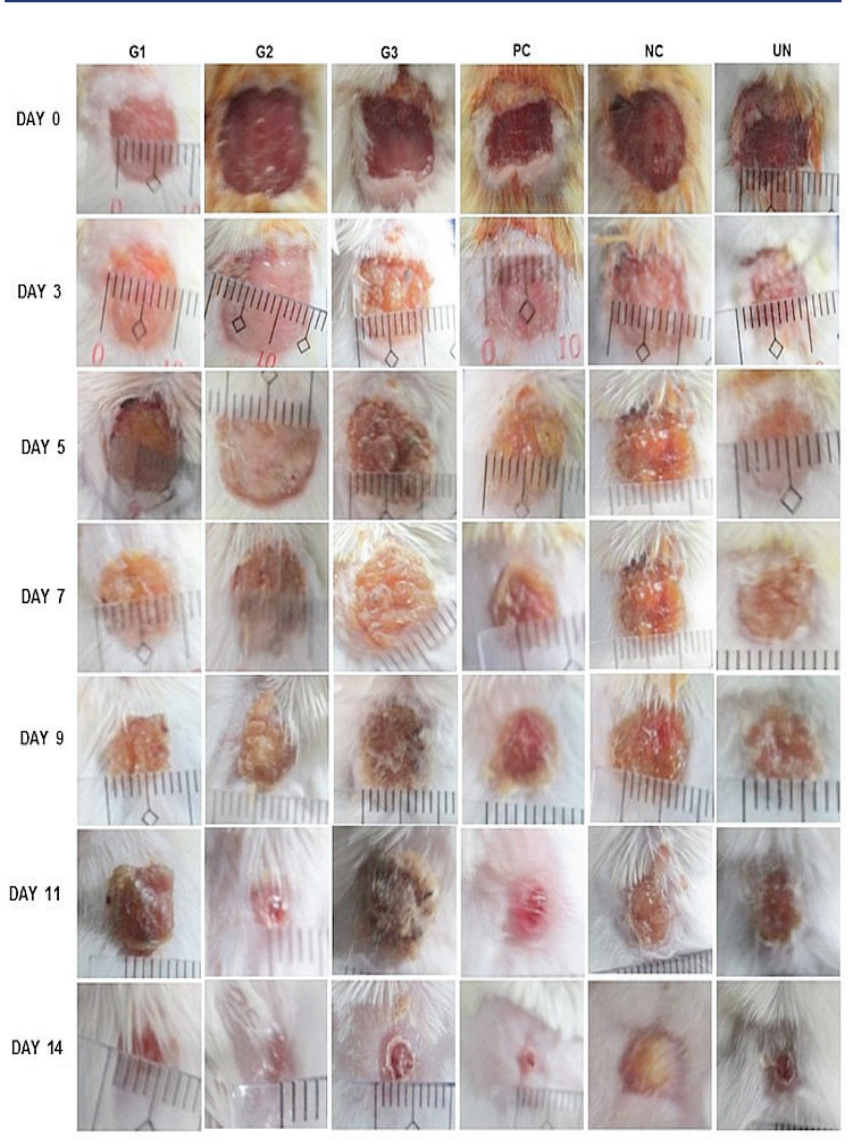

Figure 2. Wound healing progression of $C$. nucifera endosperm formulations in the excised wound generated from the BALB/c mice. $30 \%$ C. nucifera endosperm ointment (G1), 60\% C. nucifera endosperm ointment (G2), 90\% C. nucifera endosperm ointment (G3), Solcosery $1^{\triangleright}$ ointment (positive control, PC), petroleum jelly (negative control, NC), untreated (UN).

\subsection{Histological evaluation of healed wounds}

Each group was graded individually according to the presence or absence of epithelialization, inflammatory cell infiltration, fibroblast proliferation, neovascularization and collagen deposition. Control group (C), wherein no excision was made, was used as a basis for normal skin (Figure 3).

Skin wound region of G1 were mildly infiltrated with inflammatory cells on day 7 . Fibrosis was evident with increased neovascularization and enhanced proliferation of cells at day 14. Evidence of hair follicle structure development that is represented by areas of invagination of the dermis and complete re-epithelialization were also observed. 


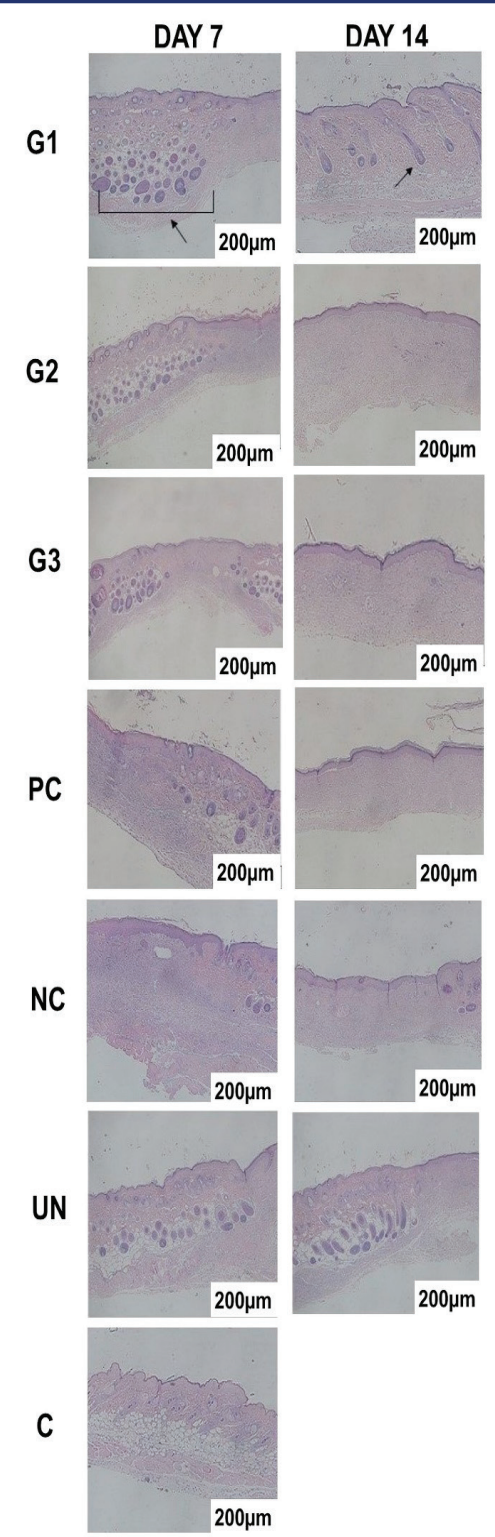

Figure 3. Histological evaluations of the healed wounds of each group after the mice were sacrificed at days 7 and $14.30 \%$ C. nucifera endosperm ointment (G1), 60\% C. nucifera endosperm ointment (G2), 90\% C. nucifera endosperm ointment (G3), Solcoseryl ${ }^{\circ}$ ointment (positive control, PC), petroleum jelly (negative control, NC), untreated (UN), control (C). Arrows indicate inflammatory cells (upper left) and hair follicle structure development (upper right).

For G2, most of the skin sections showed mild to moderate inflammatory reaction with increased angiogenesis at day 7 . Collagen formation and fibrosis was rich ranging from mild to high. At day 14, full thickness re-epithelialization was observed in which epidermis was thin and well organized comparable to normal skin. Invagination of the dermis was also found, similar to G1.
The G3 exhibited moderate to strong inflammatory reactions at day 7 in all sections. Some sections showed complete tissue re-epithelialization at day 14 with moderate to high fibroblastic proliferation, presence of modeled dense collagen mesh, and fibrosis. A thickened keratinized layer above the dermis was also observed in some sections.

For PC, skin sections showed incomplete tissue reepithelialization at day 7 with evident moderate to high infiltration of inflammatory cells and increased neovascularization. At day 14, moderate to high fibroblastic proliferation was evident. A thickened keratinized layer above the dermis was also observed in some sections.

At day 7, the skin sections of NC showed moderate to high infiltration of inflammatory cells and angiogenesis. At day 14, skin sections showed mild to moderate collagen formation. Inflammatory cells were also minimal.

For UN, skin sections showed incomplete tissue reepithelialization, mild to moderate fibroblastic proliferation and presence of modeled dense collagen mesh. Mild inflammatory reactions were also observed.

\section{DISCUSSION}

The studies on plants that have been widely utilized in traditional medicine provide a scientific basis on their efficacy in various ailments. In this study, different concentrations of C. nucifera were prepared for topical application to verify its anecdotal wound healing property.

Study on dermal irritation is an essential component for the minimum set of toxicity screening, providing a fundamental characterization of the potential hazards of the C. nucifera endosperm ointment [12]. Rabbits were used for the dermal irritation because of its high skin sensitivity, wherein even slight skin irritant effects of a substance can be detected [13]. This model has been reported as a good predictor of skin irritancy of various substances to humans $[14,15]$. In addition to rabbits, rodents have also been used but have demonstrated little capacity to respond to skin irritants [16], increasing the likelihood to have false negative results. The highest concentration was applied to increase the sensitivity and reliability of the test [17]. Based from the results, G3 showed no clinical signs of dermal irritation or corrosion, whether in the form of erythema or edema. The results corresponds to a PII value of zero, which signifies that G3 is non-irritant. The non-irritating nature of $C$. nucifera endosperm demonstrates the versatility of this product and thus, explains its traditional use for treating various diseases [6,18-19], and as food [7].

Valuable translation vehicles for human treatment modalities, which includes wound healing, are animal models [20]. In experimental wound healing assays, rodents are the most widely used animals due to their physiology that is closer to humans. Moreover, their low cost, easy handling and small 
size allow a more standardized type, size, shape and depth of wound injury, small size which allows a more standardized type, size, shape, depth of wound injury, and the fact that rodents are readily available enable the study to include a large number of samples [21 - 22], which can decrease the standard error of the results. In the present study, we used the mice model to determine the wound healing activity of ointment with $C$. nucifera endosperm as the active ingredient.

Most of the literatures reported the use of C. nucifera oil and its processed forms as effective wound healing agent. However, limited knowledge is known on the use of the C. nucifera endosperm, which is easier to obtain than the oil and other related derivatives. In this study, the highest concentration of C. nucifera endosperm in the suitable vehicle that produced no dermal irritation was used as basis in the preparation of different doses of the ointment. Among the formulated ointments, G2 gave the highest wound healing activity at days 11 and 14. Although the study did not explore the exact mechanism of wound healing of C. nucifera endosperm, its activity can be attributed to antimicrobial, anti-inflammatory and antioxidant properties. The mature C. nucifera endosperm contains $35.5 \%$ oil which can be processed to obtain the unrefined coconut oil [23]. This oil contains high amounts of lauric acid, known to have antimicrobial activity [24], and may be one of the agents responsible for the wound healing activity. The mechanism of action of lauric acid as an antibacterial agent has been known by their ability to disrupt the cell membrane of the bacteria through penetration of the fatty acid, leading to disturbance of their enzymatic system [25]. The anti-inflammatory action of lauric acid may be attributed to the inhibition of the nuclear factor kappa $B$ and mitogen activated protein kinase inflammatory cascades [26]. The endosperm also contains high amount of polyphenols, which are known antioxidants. These polyphenols reduce oxidative stress by decreasing the amount of free radicals produced by neutrophils and cytokines during an inflammatory response. In turn, this restores the optimum requirement for efficient wound healing [27]. Furthermore, the high percentage of wound closure observed in G2 is also supported by the collagen formation and fibrosis. Collagen formation and fibrosis iare parts of the proliferation process wherein a new extracellular matrix is developed in response to tissue injury [28]. This process promotes and establishes a good grip on the wound edges, bringing them together and therefore, closing the excised wound. This corroborated with the in vivo study in rodents which showed that wounded areas treated with endosperm extract healed much faster due to decreased time of complete epithelialization and higher collagen cross-linking [29].

It is noteworthy to mention that only G2 achieved comparable epidermis to normal skin and exhibited similar activity with the standard wound healing drug, Solcosery $1^{\varpi}$. This reveals that the wound healing activity of $C$. nucifera endosperm is not dose-dependent, suggesting G2 as the most effective concentration among the formulations until day 14. Products containing C. nucifera oil and its derivatives are commercially available at concentrations ranging from $0.001 \%$ to $70 \%$ [30], which display the applicability of G2 for commercial use.

\section{CONCLUSION}

This study verifies the traditional claim that $C$. nucifera endosperm possesses pro-wound healing activity, as exhibited in excision wound BALB/c mice model. Moreover, the formulation of topical dosage form directly from the $C$. nucifera endosperm saves the hassle of additional extraction processes and cost to obtain the oil. Therefore, the formulated topical $C$. nucifera endosperm from the present study may be used as a cheaper and alternative wound healing treatment.

\section{MATERIALS AND METHODS}

\subsection{Preparation of $C$. nucifera endosperm for topical application}

Twenty (20) mature coconut seedlings were harvested from the province of Cavite, Philippines. A voucher specimen (Control number: 16-06-544) was taxonomically confirmed by Danilo Tandang of the Philippine National Herbarium Botany Division and deposited to the National Museum of the Philippines. The samples were cut open and the endosperm was scraped off and homogenized. Three concentrations of C. nucifera endosperm ointments (30\%,60\% and 90\%) were prepared by trituration using petroleum jelly as vehicle to produce a homogenous paste. The $C$. nucifera endosperm concentrations were stored in sterile opaque jars at $4^{\circ} \mathrm{C}$ prior to testing of biological activity.

\subsection{Experimental animals}

Healthy BALB/c mice (20-30 g, 6-8 weeks old) were purchased from the National Institutes of Health (NIH) Animal Facility and were used for the C. nucifera wound healing experiment. Healthy albino rabbits (1000-2000 g, 5-7 weeks old) for the dermal irritation study were procured from the University of the Philippines Los Baños. All animals were housed at the animal laboratory of NIH, kept in a room with controlled temperature (23$25^{\circ} \mathrm{C}$ ) under $12 / 12 \mathrm{~h}$ light/dark cycle, with commercial food pellet and water supplied ad libitum. Acclimatization was done one week before the study, with each animal placed on separate cages. Assignment of groups to either test or to control treatments was conducted using simple randomization. All experimental procedures for the animal studies were in accordance with the guidelines of NIH and were approved by the Institute of Animal Care and Use Committee (IACUC) of the University of the Philippines Manila (approval number: 2014-021). 


\subsection{Dermal irritation test}

The procedure was based on the Organisation for Economic Co-operation and Development (OECD) guideline 404 for acute dermal irritation test [31]. Two groups with 2 rabbits each (one male and female) were used in the study. Six (6) areas of approximately $6 \mathrm{~cm}^{2}$, three on each side of the dorsal area of the trunk of each rabbit, were shaved $24 \mathrm{~h}$ before the experiment. One area was applied with $0.5 \mathrm{~g}$ of the $C$. nucifera endosperm ointment with the highest concentration (90\%) using cotton swab and held in place with a gauze patch and non-irritating tape while the other areas were left untreated (control). After $4 \mathrm{~h}$, the gauze patch was removed and the skin was rinsed with distilled water. The rabbits were observed for signs of irritation such as erythema (redness of the skin) and edema (swelling caused by accumulation of fluids) at 1, 24, 48 and $72 \mathrm{~h}$ after removal of residual formulation. The observations were graded using the OECD scoring system (Table 1). The primary irritation index (PII), which is the quantitative measurement of the acute toxic effect of substances on skin as depicted by erythema and edema, was calculated using equation 1[32]:

(Eq. 1)

$P I I=\frac{\text { EErythema }+\sum \text { Edema }(\text { at } 1,24148 \text { and } 72 h)}{\text { No.of test sites }} \times 4$ scoring intervals

\subsection{Wound healing activity}

The method for excision wound creation was adapted from Mughrabi et al. [33] with slight modifications. Thirty healthy $\mathrm{BALB} / \mathrm{c}$ mice of either sex were randomly divided into 6 groups (G1 - 30\% C. nucifera ointment; G2 - 60\% C. nucifera ointment; G3 - 90\% C. nucifera ointment; PC - Solcoseryl ${ }^{\circledR}$ as positive control; $\mathrm{NC}$ - petroleum jelly as negative control; and UN - untreated). The animals were anesthetized with 0.1 $\mathrm{mL}$ of Tiletamine/Zolazepam $\left(\right.$ Zoletil $\left.^{\circledR}\right)$ IM prior to shaving and disinfecting with $70 \%$ alcohol. The dorsal area were marked, and wounds were then created along the markings and left undressed. The wound area, ranging from 0.5-2.25 $\mathrm{cm}^{2}$, was measured immediately using a ruler.

Mice received $0.25 \mathrm{~g}$ of the samples per day except for UN, which was given no treatment. Treatments were given topically to wounded animals once daily for 14 days. Percent wound contraction, which is the healing manifestation of wound, were measured six times (days 3, 5, 7, 9, 11 and 14) to monitor the progression of wound healing. Percentage wound closure was calculated using equation 2 [34]:

(Eq. 2)

$\%$ Wound closure $=\frac{\text { Initial area of } \text { wound }- \text { nth day wound area }}{\text { Initial area of } \text { wound }} \times 100$

Table 1. Grading of skin reactions.

\begin{tabular}{|c|c|c|c|}
\hline Erythema and eschar formation & & Edema formation & \\
\hline No erythema & 0 & No edema & 0 \\
\hline Very slight erythema (barely perceptible) & 1 & Very slight edema & 1 \\
\hline Well defined erythema & 2 & Slight edema (edges of area well defined by definite rating) & 2 \\
\hline Moderate to severe erythema & 3 & Moderate edema (raised approximately $1 \mathrm{~mm}$ ) & 3 \\
\hline $\begin{array}{l}\text { Severe erythema (beef redness) to eschar formation preventing } \\
\text { grading of erythema }\end{array}$ & & $\begin{array}{l}\text { Severe edema (raised more than } 1 \mathrm{~mm} \text { and extending beyond area } \\
\text { of exposure) }\end{array}$ & 4 \\
\hline
\end{tabular}

\subsection{Histological evaluation of healed wounds}

On day 7, two mice were sacrificed for each group. Skin tissue samples were immediately fixed after animal dissection with $10 \%$ formalin, dehydrated in graded series of alcohol, cut in $2 \mu \mathrm{m}$ thick and stained with hematoxylin and eosin (H\&E). Additional sections were stained with Masson's trichome (MT) to evaluate collagen formation. Same procedure was also employed on the remaining mice after day 14 . The tissue examination was performed by a veterinary pathologist using a compound light microscope. Samples were assessed blindly for epithelialization, inflammatory cell infiltration, fibroblast proliferation, neovascularization and collagen deposition. Stained sections were graded in a blind fashion using the modified 0 to 4 numerical scale (Table 2) [35].
Table 2. Grading system for histological evaluations.

\begin{tabular}{ll}
\hline 0 & Absent \\
1 & Mild presence \\
2 & Moderate presence \\
3 & Strong presence \\
\hline
\end{tabular}

\subsection{Statistical analysis}

The data gathered were expressed as Mean \pm standard error of the mean (SEM). Statistical significance of differences between groups and control was determined by one-way analysis of variance (ANOVA), followed by Tukey's post hoc 
test using SPSS 17.0 software. Mean values were considered statistically significant when $p<0.05$.

\section{Acknowledgements}

We express our gratitude to Mr. Meliton T. Balighot for assisting us during the wound healing and dermal irritation tests. We also like to thank the National Institutes of Health Philippines for funding this study, with research grant number NIH 2013-019.

\section{Authorship statement}

Author contributions: Concept - E.C.A.; Design - E.C.A., A.A.S.; Supervision - E.C.A., A.A.S.; Materials and Resource- J.D.A.; Data Collection and/or Processing R.B.C., L.B.T., K.M.G.P., R.A.M.M., G.L.T.D.; Analysis and/ or Interpretation - R.B.C., L.B.T., K.M.G.P., R.A.M.M., G.L.T.D.; Literature Search - K.M.G.P., R.A.M.M., G.L.T.D.; Writing - R.B.C., K.M.G.P., R.A.M.M., G.L.T.D.; Critical Reviews - E.C.A., A.A.S., J.D.A., R.B.C.

\section{Conflict of interest statement}

The authors declared no conflict of interest.

\section{REFERENCES}

[1] Diegelmann RF, Evans MC. Wound healing: an overview of acute, fibrotic and delayed healing. Front Biosci. 2004; 9: 283289.

[2] Li J, Chen J, Kishner R. Pathophysiology of acute wound healing. Clin Dermatol. 2007; 25(1): 9-18.

[3] Guo S, Dipietro LA. Factors affecting wound healing. J Dent Res. 2010; 89(3): 219-229.

[4] Robles DT, Berg D. Abnormal wound healing: keloids. Clin Dermatol. 2007; 25(1): 26-32.

[5] Murphy PS, Evans GRD. Advances in wound healing: a review of current wound healing products. Plast Surg Int. 2012; Article ID 190436.

[6] Anzaldo FE, Kintanar QL, Recio RA, Velasco RU, de la Cruz F, Jacaine A. Coconut water as intravenous fluid. Philipp J Pediatr. 1975; 24(4): 143-166.

[7] Jayasekara C, Gunathilake KDPP (Eds.). Processing technologies for virgin coconut oil and coconut based confectionaries and beverages. Proceedings of International Coconut Summit. 2007 May 7-11; Kochi, India.

[8] Sylianco CYL, Guevarra AP, Wu LS, Serrame E, Mallorca R. Antigenotoxic effects of coconut endosperm, coconut milk and coconut water. Food and Agricultural Organization (FAO) of
United Nations. 1992. http://agris.fao.org/agris-search/search. do? recordID=PH9311460 (accessed September 02, 2015).

[9] Abujazia MA, Muhammad N, Shuid AN, Solaiman IN. The effects of virgin coconut oil on bone oxidative status in ovariectomised rat. Evid Based Complement Alternat Med. 2012; Article ID 525079..

[10] Ogbolu DO, Oni AA, Daini OA, Oloko AP. In vitro antimicrobial properties of coconut oil on Candida species in Ibadan, Nigeria. J Med Food. 2009; 10(2): 384-387.

[11] Nevin KG, Rajamohan T. Effect of topical application of virgin coconut oil on skin components and antioxidant status during dermal wound healing in young rats. Skin Pharmacol Physiol. 2010; 23(6): 290-297.

[12] Wang J, Li Z, Sun F, Tang S, Zhang S, Lv P, Li J, Cao X. Evaluation of dermal irritation and skin sensitization due to vitacoxib. Tox Rep. 2017; 4: 287-290.

[13] Svendsen O. Animal models in toxicological research and toxicity testing. In: Svendsen P and Hau J. (Eds). Handbook of Laboratory Animal Science Volume II: Animal Models. CRC Press, New York, 1994, pp. 11.

[14] Sanders A. Acute dermal irritation in the rabbit. Harlan. 2007; pp. 1-14.

[15] Fitzhugh OG, Woodard G, Braun HA. The toxicities of compounds related to 2,3-dimercaptopropanol (BAL) with a note on their relative therapeutic efficiency. J Pharmacol Exp Ther. 1946; 87: 23-27.

[16] Roper SS. Dermatotoxicology: animal irritancy testing. In: Rietschel RL and Spencer TS (Eds). Methods for Cutaneous Investigation. Narcel Dekker, Inc, New York, 1990, pp. 22-24.

[17] Api AM. The use of human data when conducting dermal sensitization quantitative risk assessments for fragrance ingredients. In: World Health Organization, International Program on Chemical Safety. Skin Sensitization in Chemical Risk Assessment. WHO, 2008, pp. 23.

[18] Zakaria ZI, Rezal I, Mat Jais AM, Somchit MN, Sulaiman MR, Marmin AHI, Sidek H, Husin SH, Rahim MHA, Abdul Rahman L. The anti-inflammatory, anti-pyretic and wound healing activities of Cocos nucifera (MATAG types) fresh juice and kernel extract in experimental animals. J Pharmacol Toxicol. 2006; 1(6): 516-526.

[19] Singla Rk. Review on the pharmacological properties of Cocos nucifera endocarp. Webmed Central Pharm Sci. 2012; 3(5) WMC003413. doi: 10.99754/jurnal.wmc.2012.003413.

[20] Seo BF, Lee JY, Jung SN. Models of abnormal scarring. Biomed Res Int. 2013. Article ID 423147. doi: 10.115/2013/423147.

[21] Trostrup H, Thomsen K, Calum H, Hoiby N, Moser C. Animal models of chronic wound care: the application of biofilms in clinical research. Chronic Wound Care Manag Res. 2016; 3: 123-132.

[22] Dorsett-Martin WA, Wysocki AB. Rat models of skin wound healing. In: Conn PM (ed) Sourcebook of Models for Biomedical rseearch. Humana Press, New Jersey, 2008, pp. 631.

[23] Solangi AH, Iqbal MZ. Chemical composition of endosperm (kernel) and nut water of major coconut (Cocos nucifera L.) cultivars at coastal area of Pakistan. Pak J Bot. 2011; 43(1):357-363. 
[24] Narong C. Review article 181: Health and economic benefits of coconut oil production development in Thailand. AU JT. 2011; 14(3): 181-187.

[25] Bergsson G, Arnfinnsson J, Steingrimsson O, Thormar H. In vitro killing of Candida albicans by fatty acids and monoglycerides. Antimicrob Agents Chemother. 2001; 45(11): 3209-3212.

[26] Huang WC, Tsai TH, Chuang LT, Li YY, Zouboulis CC, Tsai PJ. Antibacterial and anti-inflammatory properties of capric acid against Propionibacterium acnes: a comparative study with lauric acid. J Dermatol. 2014; 73(3): 232-240.

[27] Shetty S, Udupa S, Udupa L. Evaluation of antioxidant and wound healing effects of alcoholic and aqueous extract of Ocimum sanctum Linn. in rats. Evid Based Complement Alternat Med. 2008; 5(1): 95-101.

[28] Kendall RT, Feghali-Bostwick CA. Fibroblasts in fibrosis; novel roles and mediators. Front Pharmacol. 2014; 5: 123.

[29] Batool SH. The effect of coconut oil extract on full thickness wound healing on the female rabbits. Bas J Vet Res. 2012; 11(2): 28-34.

[30] Burnett CL, Bergfeld WF, Belsito DV, Klaassen CD, Marks JG Jr, Shank RC, Slaga TJ, Synder PW, Andersen FA. Final report on the safety assessment of Cocos nucifera (Coconut) oil and related ingredients. Int J Toxicol. 2011; 30(S1): 5S-16S.

[31] Organisation for Economic Cooperation and Development (OECD) 404. OECD guideline for the testing of chemical. Acute dermal irritation/corrosion. 2002. https://eurl.ecvam.jrc.ec.europa. eu/validation-regulatory-acceptance/docs-skin-irritation-1/ DOC2_OECD-TG-404.pdf (accessed September 02, 2015)w.

[32] Soiefer, AI, Rauckman EJ. Toxicity associated with single chemicla exposures. In: Jacobson-Kram D, Keller KA. (Eds). Toxicology Testing Handbook Priciples, Applications, and Data Applications. Marcel Dekker Inc., New York, 2001, pp. 28.

[33] Mughrabi FF, Hashim H, Ameen M, Khaledi H, Ali HM, Ismail S. Effect of bis[benzyl N'-indol-3-ylmethylene)hydrazinecarbodithioato-zinc (II) derivatives on wound healing in Sprague Dawley rats. Indian J Exp Biol. 2011; 49(1): 50-55.

[34] Singhal AK, Gupta H, Bhati VS. Wound healing activity of Argyreia nervosa leaves extract. Int J App Basic Med Res. 2011; 1(1): 36-39.

[35] Pereira DT, Lima-Riberio MHM, de Pontes-Filho NT, Carniero-Leao AM, Correira MT. Development of animal model for studying deep second-degree thermal burns. J Biomed Biotech. 2012. Article ID 460841. 